\title{
Critical analysis of drug related problems among inpatients in the psychiatry department of a tertiary care teaching hospital: A pharmacist led initiative
}

\author{
Anjali Jayakumar ${ }^{\mathrm{a}}$, Achsa Shekaina Abraham ${ }^{\mathrm{a}}$, Shishir Kumar ${ }^{\mathrm{b}}$, Sharad Chand ${ }^{\mathrm{a}}$, \\ Sophia M. George ${ }^{\text {a }}$, Juno J. Joel ${ }^{\text {a }}$, Nandakumar UP ${ }^{\text {a, }}$ \\ ${ }^{a}$ Nitte (Deemed to be University), Nitte Gulabi Shetty Memorial Institute of Pharmaceutical Sciences (NGSMIPS), Department of Pharmacy Practice, Mangaluru, \\ 575018, India \\ ${ }^{\mathrm{b}}$ Department of Psychiatry, Justice K.S. Hegde Charitable Hospital, Mangalore, Karnataka, 575018, India
}

\section{A R T I C L E I N F O}

\section{Keywords:}

DRP

APS-Doc classification

Incorrect spelling

ADR

Wrong dosage form

\begin{abstract}
A B S T R A C T
Introduction: Drug Related Problems (DRPs) frequently take place in modern medical practices, increasing the morbidity and mortality as well as the cost of patient care.

Objective: The current study was undertaken to identify and evaluate various DRPs among the inpatients of the psychiatry department in a tertiary care teaching hospital using APS-Doc classification system and to identify the most recurrent drugs causing the DRPs.

Method: ology: A prospective observational study was conducted forduration of six months among 198 patients using APS-Doc classification system. The data was statistically analysed and tabulated.

Results: A total of 205 DRPs were identified in 102 patients, among which 115 (56.1\%) were potential drug-drug interactions (pDDI) and $62(30.2 \%)$ were adverse drug reactions (ADRs). 21 (10.2\%) DRPs belonged to the category of incorrect spelling of the trade name and $3(1.5 \%)$ among them belonged to unintended prescription of the same drug. Two out of 205 DRPs (1\%) belonged to the class of prescription of an incorrect dosage form or no dosage prescribed. One DRP each were categorised under wrong dosage form prescribed and inadequate generic substitution respectively. Out of the total of 314 drugs, risperidone $(n=43,13.7 \%)$ was found to be the drug associated with the most number of DRPs followed by olanzapine $(\mathrm{n}=38,12.1 \%)$ and lorazepam $(\mathrm{n}=32$, $10.2 \%$ ).

Conclusion: The study revealed that more than half $(51.5 \%)$ of the patients presented with DRPs and the most commonly identified DRPs were pDDIs and ADRs.
\end{abstract}

\section{Introduction}

A Drug-Related Problem (DRP) is an event or circumstance involving drug therapy that actually or potentially interferes with desired health outcomes. DRPs adversely affect the health care, expenditure, morbidity, quality of life, extent of the hospitalization and mortality. ${ }^{1}$ Out of several available systems to identify the DRPs, the APS-Doc classification system is one among the most commonly used to categorize DRPs in majority of the studies. It consists of 10 main categories and 48 sub-categories. ${ }^{2}$ The use of the same classes of psychotropic medicines in the treatment of different psychiatric disorders has contributed to the increasing frequency of drug related problems in psychiatric patients. ${ }^{3,4}$ Advanced age, concurrent use of multiple psychotropic drugs, polypharmacy and changes in the drug metabolism (due to comorbid conditions) can predispose a patient to DRPs. ${ }^{5}$ Thus, it is crucial to prevent them to minimize the harm to patients.Timely detection of DRPs can improve the health care outcomes, costs and patient's satisfaction. ${ }^{1}$ A clinical pharmacist can play a crucial role in optimizing and individualizing therapy. ${ }^{6}$ They can recommend the most economical and feasible way to identify the DRPs and suggest the best possible alternatives. They should also tailor an individualized pharmaceutical care plan for the prevention, identification and resolution of DRPs. ${ }^{7}$ The

\footnotetext{
* Corresponding author. Nitte (Deemed to be University), Nitte Gulabi Shetty Memorial Institute of Pharmaceutical Sciences (NGSMIPS), Department of Pharmacy Practice, Deralakatte, Mangaluru, 575018, India.

E-mail address: nandakumarvtkv@gmail.com (N. UP).
} 
knowledge of the pharmacist in the quality use of medicines through evidence based practice and their ability to find the correlation between the patient's condition and the pharmacotherapeutic outcomes is crucial in cataloguing different DRPs. The services of a clinical pharmacist are under-utilized in several underdeveloped and developing countries and India is not an exception. An optimal service by a clinical pharmacist helps in designing a safe, effective and economic treatment regimen. ${ }^{1,7}$ With this concept, we aim to identify and evaluate various DRPs among the inpatients of the psychiatry department in a tertiary care teaching hospital using the APS-Doc classification system and identify the drugs recurrently causing them.

\section{Methodology}

A prospective, observational study was conducted in the department of psychiatry for aperiod of six months after obtaining approval from the Institution Ethics Committee (IEC) Ref No: NGSMIPS/IEC/20/2019-20. A required sample size of 198 patients was calculated based on the prevalence of DRP from the previous studies. ${ }^{8}$ Patients of either gender above 18 years of age, admitted in the department of psychiatry, diagnosed with a psychiatric disorder and prescribed with at least one drug were included in the study. Patients not satisfying the inclusion criteria were excluded from the study. Data was collected after getting permission from the hospital and unit authorities in a suitably designeddata collection formas per the need of the study. The first section of data collection form included the socio-demographic details such as age, gender, domiciliary status, and social habits. The second section included details like comorbidities and diagnosis, therapeutic information about the drugdose, dosage form, route of administration and treatment duration. A separate DRP form was designed based on the APS-Doc classification system. APS-Doc classification system has 10 main categories like drugs, dosage form/dosage strength, dosage, indication, contraindications, drug-drug interactions (DDI), adverse drug reactions (ADR), administration/compliance, application and others with 48 sub-categories. The DRP forms also carried detailed explanations on the identified drug related problems. During the course of the study, the investigators (academic pharmacist) attended the ward rounds on a daily basis and collected all the relevant data from patient case files. The investigators equally participated in the drug therapy monitoring for optimal patient care. When DRPs were identified, they were promptly brought to the notice of the treating physicians and were verified by the physician and the clinical pharmacist before final documentation. Data collection was done on a DRP form tailored to meet the objectives of the study. The ADRs that were identified were documented using suspected ADR reporting form by central drugs standard control organization and communicated to the regional pharmacovigilance authorities regularly.

Statistical analysis: All the collected data was coded after masking the patient's identity. Data was entered in the SPSS (Version 20.0) software and was cross-checked with the collected data for any errors. The final data was analysed and the results were summarized as frequency with percentage for qualitative variables. Mean and standard deviation were used to analyse and tabulate the quantitative variables.

\section{Results}

\subsection{Distribution of socio-demographic details of the patients}

A total of 198 inpatients of the psychiatry department were enrolled in the study. Out of the total study population, Majority ( $\mathrm{n}=145$, $73.2 \%)$ were males and only $(n=53,26.8 \%)$ were females. Majority of the subjects were found belonging to the age group of 30-39 years $(\mathrm{n}=$ $62,31.3 \%$ ) followed by $18-29$ years $(n=50,25.3 \%)$. Most of the study population came from rural areas $(n=114,57.6 \%)$. Among the total study subjects, 93 were reported to have at least one social habit. Out of this, ( $\mathrm{n}=33,35.4 \%$ ) were found to have the habit of both alcohol consumption and smoking and $(\mathrm{n}=28,30.1 \%)$ patients were found to be alcoholics alone with no other social habits. The average duration of hospital stay of a patient was found to be 28.7 days from an overall range of 1-80 days. Similarly, $(\mathrm{n}=98,49.5 \%)$ patients were admitted in the hospital for a period of $21-40$ days and $(n=57,28.7 \%)$ patients were admitted for a period of 1-20 days. Out of the total 71 co-morbidities reported, diabetes mellitus ( $\mathrm{n}=32,45.1 \%$ ) was found to be the most common comorbidity followed by hypertension $(n=15,21.1 \%)$. The details are summarized in Table 1.

\subsection{Distribution of subjects based on their diagnosis}

Alcohol dependence syndrome (ADS) ( $n=67,26.1 \%$ ) was found to be the most commonly diagnosed disorder followed by schizophrenia (n $=49,19.1 \%$ ). The details on the distribution of subjects based on their diagnosis are illustrated in Fig. 1.

\subsection{Distribution of subjects based on the psychotropic prescribed}

In the study population, antipsychotic agents and sedatives were found to be the most commonly prescribed drugs. Majority were prescribed with typical antipsychotics $(n=85,42.9 \%)$ alone followed by a combination of typical and atypical antipsychotics ( $n=56,28.2 \%)$. Among the various psychotropic drugs, lorazepam was prescribed the most $(n=70,14.8 \%)$ followed by risperidone $(n=54,11.4 \%)$. The details on the prescribed psychotropics are summarized in Fig. 2.

\subsection{Distribution of subjects based on the occurrence of DRPS}

A total of $n=102,51.5 \%$ patients presented with DRPs and the rest

Table 1

Distribution of study population based on their demographics.

\begin{tabular}{ll}
\hline Age & Frequency (Percentage) \\
$18-29$ & $50(25.25 \%)$ \\
$30-39$ & $62(31.31 \%)$ \\
$40-49$ & $29(14.64 \%)$ \\
$50-59$ & $36(18.18 \%)$ \\
$60-69$ & $18(9.09 \%)$ \\
$70-79$ & $3(1.51 \%)$ \\
Total & $198(100 \%)$ \\
Gender & \\
Male & $145(73.2 \%)$ \\
Female & $53(26.8 \%)$ \\
Total & $198(100 \%)$ \\
Social Habits & \\
Alcohol + Smoking & $33(35.4 \%)$ \\
Alcohol & $28(30.1 \%)$ \\
Smoking & $20(21.5 \%)$ \\
Smoking + Substance abuse & $4(4.3 \%)$ \\
Substance abuse & $3(3.2 \%)$ \\
Alcohol + Smoking + Substance abuse & $3(3.2 \%)$ \\
Alcohol + Substance abuse & $2(2.1 \%)$ \\
Total & $\mathbf{9 3}(100 \%)$ \\
Domiciliary Status & \\
Rural & $114(57.6 \%)$ \\
Urban & $84(42.4 \%)$ \\
Total & $198(100 \%)$ \\
Length of Hospital Stay & \\
$0-20$ & $57(28.7 \%)$ \\
$21-40$ & $98(49.49 \%)$ \\
$41-60$ & $42(21.2 \%)$ \\
61-80 & $1(0.5 \%)$ \\
Total & $198(100 \%)$ \\
Co-Morbidities & \\
Diabetes Mellitus & $32(45.1 \%)$ \\
Hypertension & $15(21.1 \%)$ \\
Thyroid Disorders & $12(17 \%)$ \\
Ischemic Heart Disease & $7(9.8 \%)$ \\
Anaemia & $4(5.6 \%)$ \\
Osteoporosis & $1(1.4 \%)$ \\
Total & $\mathbf{7 1 ( 1 0 0 \% )}$ \\
\hline & \\
&
\end{tabular}




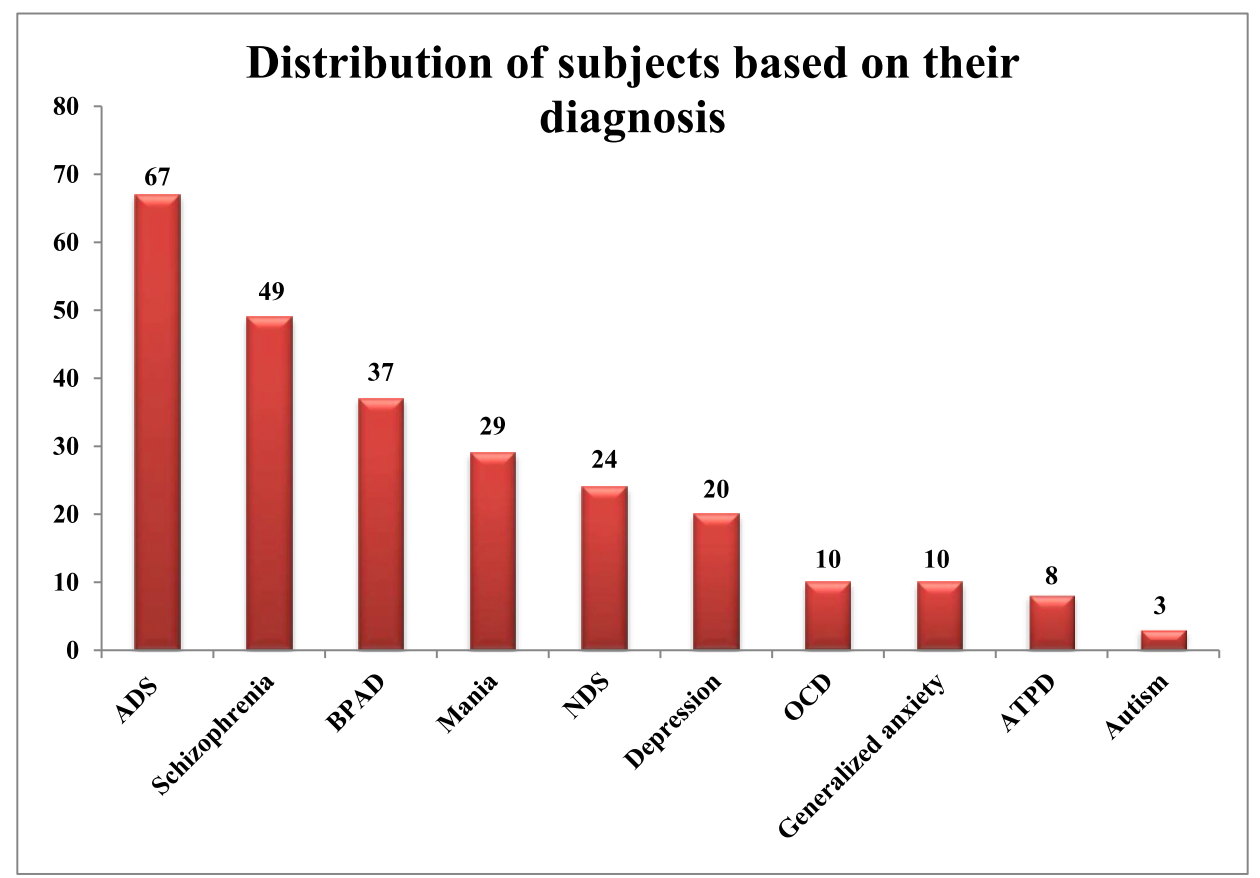

Fig. 1. Distribution of subjects based on their diagnosis BPAD: Bipolar Affective Disorder, OCD: Obsessive Compulsive Disorder, ADS: Alcohol Dependence Syndrome, NDS: Nicotine Dependence Syndrome, ATPD: Acute Transient Psychotic Disorder.

\section{Distribution of subjects based on the psychotropics prescribed}

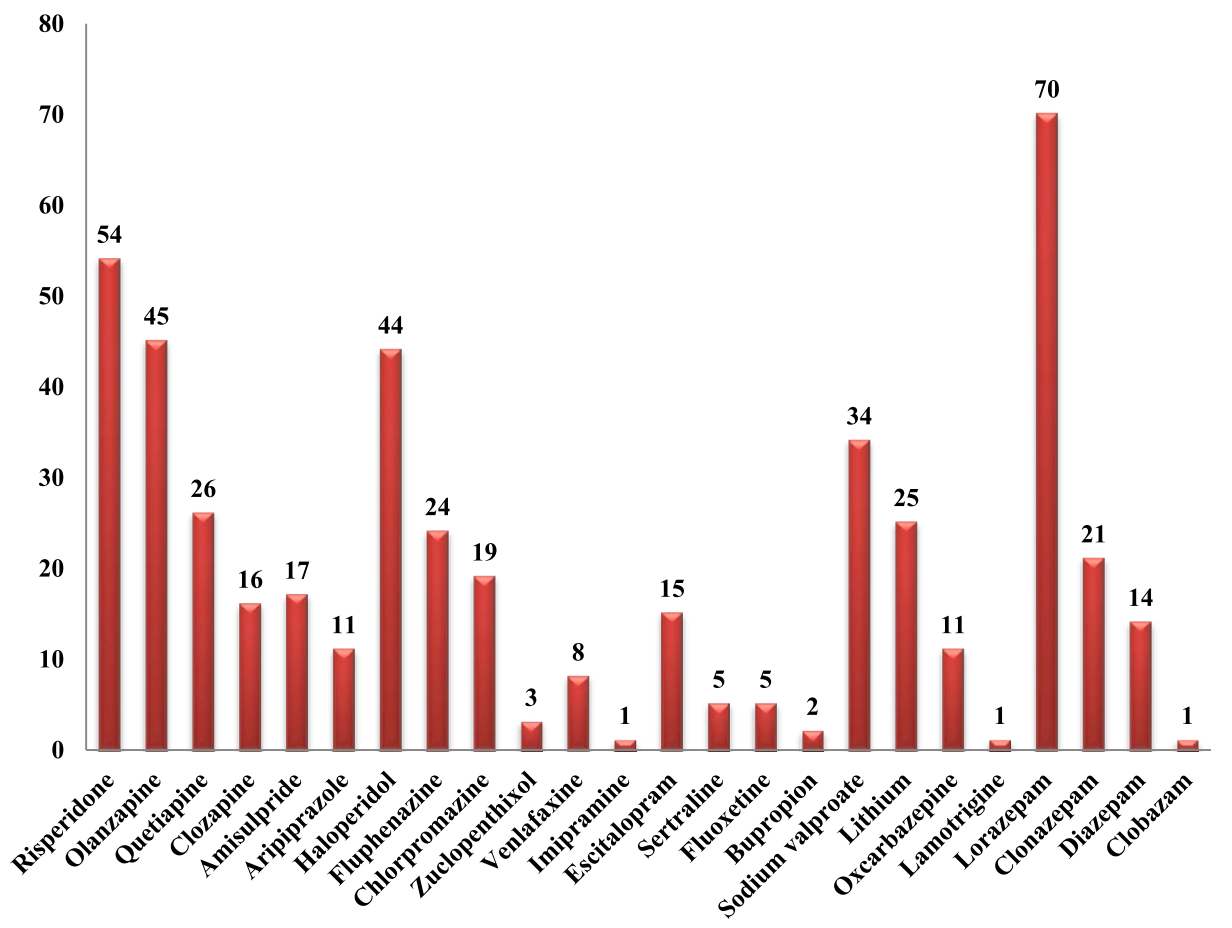

Fig. 2. Distribution of subjects based on the psychotropics prescribed.

were not identified with DRPs. The average frequency of DRPs was 1.02 per patient. One hundred ninety one out of 198 (96.4\%) were nongeriatric patients and $(\mathrm{n}=7,3.53 \%)$ were geriatric patients. Among the total 191 non-geriatric subjects, $(n=98,51.3 \%)$ were found to have one or more DRPs and among the 7 geriatric subjects, $(n=4,57.1 \%)$ presented with DRPs.
3.5. Distribution of different classes of DRPs according to the APS-Doc system of classification

Out of 198 subjects enrolled in the study, 102 patients presented a total of 205 DRPs. The most common DRP was found to be pDDIs ( $\mathrm{n}=$ $115,56.1 \%)$ followed by ADRs $(n=62,30.2 \%)$. The details on different 
classes of DRPs are referenced in Table 2.

\subsection{Distribution of drugs associated with DRPs}

Out of 205 DRPs identified among a total of 314 prescribed drugs, risperidone $(n=43,13.7 \%)$ was found to be the drug associated with the most number of DRPs followed by olanzapine $(\mathrm{n}=38,12.1 \%)$ and lorazepam $(\mathrm{n}=32,10.2 \%)$. The frequency distribution of drugs associated with DRPs is shown in Table 3.

\subsection{Distribution of subjects based on the occurrence and distribution pattern of ADRs}

In a total of 198 subjects, $(\mathrm{n}=39,19.7 \%)$ were identified with at least one ADR and $(n=159,80.3 \%)$ were identified with none. Table 4 illustrates the details on incidence of ADRs. A total of 62 ADRs were found in 39 patients. $(n=15,24.2 \%)$ cases of daytime drowsiness and ( $n=9,14.5 \%$ ) cases of cogwheel rigidity top the list of the most commonly occurring ADRs. Out of the 62 ADRs that were identified, antipsychotic agents $(n=41,66.1 \%)$ followed by sedatives $(n=11$, $17.7 \%$ ) presented with the most number of ADRs. Olanzapine and clozapine belonging to the class of atypical antipsychotic agents caused the most number of ADRs, that is $(n=20,32.2 \%)$ and $(n=10,16 \%)$ respectively.

\subsection{Distribution of subjects based on pDDIs}

Out of 198 study subjects, $(n=60,30.3 \%$ ) patients were found to have pDDI and $(\mathrm{n}=138,69.7 \%)$ patients did not have any pDDI. The pDDI were categorised as minor, moderate and major according to their degree of severity using the UptoDate software. Out of $115 \mathrm{pDDI},(\mathrm{n}=7$, $6.1 \%)$ were minor, $(n=50,43.5 \%)$ were moderate and $(n=58,50.4 \%)$ were major. The combinations of haloperidol + chlorpromazine and amisulpride + risperidone were seen $(n=7,6.1 \%)$ times and lorazepam + olanzapine and lorazepam + sodium valproate were seen $(n=6$, $5.2 \%)$ times.

\section{Discussion}

This study included 198 patients satisfying the study criteria, admitted in the department of psychiatry of a tertiary care teaching hospital in coastal Karnataka. The main focus of the study was to assess the drug related problems among the inpatients and to find out the most frequent drugs that are associated with DRPs.

In the present study, the male population $(73.2 \%)$ outnumbered the female population $(26.8 \%)$ which is similar to the study conducted by

Table 2

Distribution of different classes of DRPs according to the APS-Doc system of classification.

\begin{tabular}{|c|c|c|c|}
\hline $\begin{array}{l}\text { Classification of } \\
\text { DRP }\end{array}$ & $\begin{array}{l}\text { Sub-class } \\
\text { of DRP }\end{array}$ & Description of DRP & $\begin{array}{l}\text { Frequency } \\
(\%)\end{array}$ \\
\hline \multirow[t]{3}{*}{ Drug } & $\mathrm{Rx} 1$ & $\begin{array}{l}\text { Incorrect spelling of the trade } \\
\text { name }\end{array}$ & $21(10.2 \%)$ \\
\hline & $\mathrm{Rx} 7$ & $\begin{array}{l}\text { Inadequate generic } \\
\text { substitution }\end{array}$ & $1(0.5 \%)$ \\
\hline & $\mathrm{Rx} 9$ & $\begin{array}{l}\text { Unintended prescribing of the } \\
\text { same drug }\end{array}$ & $3(1.5 \%)$ \\
\hline $\begin{array}{l}\text { Dosage Form/ } \\
\text { Dosage Strength }\end{array}$ & DS1 & Wrong dosage form prescribed & $1(0.5 \%)$ \\
\hline Dosage & DOS2 & $\begin{array}{l}\text { Prescription of an incorrect } \\
\text { dosage or no dosage } \\
\text { prescribed }\end{array}$ & $2(1 \%)$ \\
\hline $\begin{array}{l}\text { Drug-Drug } \\
\text { Interaction }\end{array}$ & DDI1 & $\begin{array}{l}\text { Potential drug-drug } \\
\text { interaction }\end{array}$ & $115(56.1 \%)$ \\
\hline $\begin{array}{l}\text { Adverse Drug } \\
\text { Reaction }\end{array}$ & ADR1 & Symptoms of an ADR & $62(30.2 \%)$ \\
\hline Total & & & $205(100 \%)$ \\
\hline
\end{tabular}

Table 3

Distribution of drugs associated with DRPs.

\begin{tabular}{lll}
\hline Drugs & Frequency & Percentage (\%) \\
\hline Risperidone & 43 & 13.7 \\
Olanzapine & 38 & 12.1 \\
Lorazepam & 32 & 10.2 \\
Amisulpride & 29 & 9.2 \\
Clozapine & 26 & 8.3 \\
Chlorpromazine & 24 & 7.6 \\
Haloperidol & 21 & 6.7 \\
Sodium valproate & 17 & 5.4 \\
Zuclopenthixol & 15 & 4.8 \\
Aripiprazole & 12 & 3.8 \\
Clonazepam & 12 & 3.8 \\
Quetiapine & 6 & 2.0 \\
Escitalopram & 6 & 2.0 \\
Oxcarbazepine & 6 & 2.0 \\
Lithium & 6 & 2.0 \\
Fluoxetine & 5 & 1.6 \\
Fluphenazine & 4 & 1.3 \\
Diazepam & 3 & 1.0 \\
Trihexyphenidyl & 3 & 1.0 \\
Phenytoin & 2 & 0.6 \\
Sertraline & 2 & 0.6 \\
Venlafaxine & 1 & 0.3 \\
Imipramine & 1 & 0.3 \\
Total & 314 & 100 \\
\hline
\end{tabular}

Table 4

Distribution pattern of ADRs among the study subjects.

\begin{tabular}{|c|c|c|c|}
\hline ADR & $\begin{array}{l}\text { Frequency } \\
\text { (n) }\end{array}$ & $\begin{array}{l}\text { Percentage } \\
(\%)\end{array}$ & Drugs \\
\hline $\begin{array}{l}\text { Daytime } \\
\text { drowsiness }\end{array}$ & 15 & 24.2 & $\begin{array}{l}\text { Olanzapine (4), Lorazepam (3), } \\
\text { Clozapine (1), Risperidone (1), } \\
\text { Lithium (1), Oxcarbazepine (1), } \\
\text { Venlafaxine (1), Clonazepam (1) }\end{array}$ \\
\hline $\begin{array}{l}\text { Cogwheel } \\
\text { rigidity }\end{array}$ & 9 & 14.5 & Olanzapine (5), Risperidone (4) \\
\hline Constipation & 7 & 11.3 & $\begin{array}{l}\text { Olanzapine (2), Lorazepam (2), } \\
\text { Clozapine (2), Risperidone (1) }\end{array}$ \\
\hline Tremors & 5 & 8.1 & $\begin{array}{l}\text { Olanzapine (2), Clozapine (1), } \\
\text { Lithium (1), Sodium valproate } \\
\text { (1) }\end{array}$ \\
\hline Sialrrhoea & 3 & 4.8 & Clozapine (2), Aripiprazole (1) \\
\hline Weight gain & 2 & 3.2 & Olanzapine (2) \\
\hline Dystonia & 2 & 3.2 & $\begin{array}{l}\text { Olanzapine (1), Chlorpromazine } \\
\text { (1) }\end{array}$ \\
\hline Slurred speech & 2 & 3.2 & Olanzapine (2) \\
\hline Skin rashes & 2 & 3.2 & $\begin{array}{l}\text { Lorazepam (1), Trihexyphenidyl } \\
\text { (1) }\end{array}$ \\
\hline Tachycardia & 2 & 3.2 & Clozapine (2) \\
\hline Akathisia & 2 & 3.2 & Clozapine (2) \\
\hline $\begin{array}{l}\text { Tardive } \\
\text { dyskinesia }\end{array}$ & 2 & 3.2 & Amisulpride (2) \\
\hline $\begin{array}{l}\text { Menstrual } \\
\text { irregularity }\end{array}$ & 1 & 1.6 & Olanzapine (1) \\
\hline Pedal oedema & 1 & 1.6 & Olanzapine (1) \\
\hline Restlessness & 1 & 1.6 & Lorazepam (1) \\
\hline $\begin{array}{l}\text { Itching in the } \\
\text { groin }\end{array}$ & 1 & 1.6 & Lorazepam (1) \\
\hline Dark stools & 1 & 1.6 & Risperidone (1) \\
\hline Seborrhoea & 1 & 1.6 & Sodium valproate (1) \\
\hline Rhinorrhoea & 1 & 1.6 & Trihexyphenidyl (1) \\
\hline Itching & 1 & 1.6 & Trihexyphenidyl (1) \\
\hline Cough & 1 & 1.6 & Clonazepam (1) \\
\hline Total & 62 & 100 & - \\
\hline
\end{tabular}

Wali SC et al., in which the number of male patients (60\%) was higher compared to the females (40\%). ${ }^{3}$ In this study, the age group with the most number of admissions was found to be $30-39$ years (31.3\%) which is similar to the study conducted by Mukherjee $S$ et al., which reported that $35.7 \%$ of the study subjects belonged to the age group of $30-39$. $^{9}$ However, these results are different from the findings of the study 
conducted by Wali SC et al., in which the majority of the patients belonged to the age group of $21-30$ years (40\%). ${ }^{3}$ The reason for this variation maybe attributed to the predisposing risk factors like alcohol abuse that come with lifestyle and geographic differences of these study populations. Forty two percentage of the subjects enrolled in the study were from urban background which is similar to the study conducted by Grover S et al., in which nearly half of the patients belonged to the urban background. ${ }^{10}$ The present study reported that the median length of hospital stay of the patients was 36.5 days whereas a study done by Newman L et al., revealed that the median length of stay to be 19 days. ${ }^{11}$ These values may differ yet again since re-admissions of the same patients were not accounted in either study.

Diabetes mellitus (45.1\%) was found to be the most commonly occurring co-morbidity in the study population. This was followed by hypertension which was present in $21.1 \%$ of the total study population. This result is in concordance with that of the study carried out by Zolezzi $\mathrm{M}$ et al., which also established diabetes mellitus (16.1\%) and hypertension $(9.8 \%)$ as the two most commonly occurring co-morbidities. ${ }^{12}$ In the present study, alcohol consumption (70.9\%) along with smoking (64.5\%) topped the list of the most common social habits among the study subjects. A study conducted by Singh SG et al., also reported alcohol (84\%) and smoking (61\%) as the most common social habits among psychiatry patients. ${ }^{13}$ This explains why majority of the study subjects were diagnosed with recreational drug-induced addictive disorders in this study.ADS and schizophrenia were the two most common diagnoses in the study population. In a study done by Khoda DA et al., schizophrenia and bipolar affective disorder were highest in number. ${ }^{14}$ The high frequency of ADS in the present study population can be because of the high frequency of alcoholics in the location where the study was conducted. Similarly, the most frequently prescribed class of drug was found to be atypical antipsychotics which constitute $35.7 \%$ of the total psychotropic drugs prescribed. This finding is contradictory to the results of the study done by Wali SC et al., in which typical antipsychotics topped the list in prescription pattern analysis. ${ }^{3}$ The higher prescription rate of atypical antipsychotics may be due to the clinical judgement and experience of the physicians-in-charge about what works best therapeutically and economically for the patient population.

The present study revealed that $51.5 \%$ of the study population developed at least one DRP. Nevertheless, this outcome is different from that of a study done by Mateti UV et al., in which the overall incidence of DRP was only $15.8 \% .{ }^{15}$ The higher incidence in the present study can be put down to multiple contributing factors like age, co-morbidities, polypharmacy and drug abuse. ${ }^{5}$ The findings of the present study showed that incidence of DRPs were higher in male patients belonging to the age group of 30-39 years whereas in a study conducted by Mateti UV et al., higher rate of DRPs were present in female patients particularly in the age group of 40-60 years. ${ }^{15}$ These contradictory results may be due to the predominance of male subjects that constituted almost 3/4th of the study population. In the present study, the higher incidence of DRPs in the age group of 30-39 years may be attributed to the susceptibility of younger patients to recreational activities like smoking, alcohol and substance abuse. This requires them to take more medications which in turn predispose them to the development of more DRPs.

The study also concluded that $56.1 \%$ of the DRPs were potential DDIs and $30.2 \%$ were ADRs. In the study done by Wali SC et al., $44.4 \%$ of the DRPs were ADRs and $11.1 \%$ were DDIs. ${ }^{3}$ It can be theorized that polypharmacy and co-morbidities contributed significantly to this high incidence of DRPs. Out of the 62 ADRs that were identified and reported in this study, the most frequently occurring ADRs were daytime drowsiness and cogwheel rigidity. In an ADR study conducted by Sridhar SB et al., weight gain and somnolence were reported the most number of times. ${ }^{16}$ The present study indicated that olanzapine followed by clozapine caused the most number of ADRs in the subjects, whereas in the study done by Sridhar SB et al.,escitalopram and quetiapine topped the list. ${ }^{16}$ This variation may be accredited to the difference in prescribing patterns. According to their degree of severity, $50.4 \%$ of them were found to be major and $43.5 \%$ were moderate. This is dissimilar to an existing study done by AlRuthia $\mathrm{Y}$ et al.,in which $46.1 \%$ were moderate and only $32.2 \%$ were major. ${ }^{17}$ Majority of the psychiatric patients exhibit multiple co-morbidities which can be again due to the various metabolic risks associated with the antipsychotic therapy. ${ }^{18}$ The psychotropic agents along the drugs used for management of these co-morbidities can lead to changes in the metabolism resulting in drug-drug interactions. This study assessed the incidence of drug related problem among psychiatric patients. All the identified ADRs were reported to the treating physician and the pharmacovigilance centre but the other type of DRPs according to the APS-Doc criteria were not resolved by the pharmacist and is a major limitation of this study. The authors suggest the conduct of further studies among psychiatric patients to identify and resolve these DRPs through an active participation with the clinical pharmacist.

\section{Conclusion}

Out of the total subjects enrolled in the study, 102 patients presented with a total of 205 DRPs. The most common DRP was found to be pDDIs followed by ADRs. The drugs associated with the most number of DRPs were risperidone followed by lorazepam. DRPs significantly contribute in increasing the financial burden on the patients. Therefore, proper identification and reporting of the DRPs may help to factor in their economic impact. The study also concludes the importance of the participation of a clinical pharmacist in the identification of DRPs among patients prescribed with psychotropic agents. Hence, clinical pharmacists play a vital role to ensure the safe and judicious use of medicines.

\section{Source of funding}

Nil.

\section{Declaration of competing interest}

Authors declare no conflict of interest.

\section{Acknowledgement}

We authors would like to thank the officials of Justice KS Hegde Charitable Hospital for their support during the study.

\section{References}

1 Roy DA, Shanfar I, Shenoy P, Chand S, Nandakumar UP, Raj BKC. Drug-related problems among chronic kidney disease patients: a pharmacist led study. International Journal of Pharmaceutical Research. 2020;12:79-84, 04.

2 Hohmann C, Eickhoff C, Klotz JM, Schulzm M, Radziwill R. Development of a classification system for Drug Related Problems in the hospital setting (APS-Doc) and assessment of the inter-rater reliability. J Clin Pharm Therapeut. 2012;37(3):276-281.

3 Wali SC, Ganachari MS, Parihar AS, Sonawale SB. Impact of clinical pharmacist in the monitoring of drug related problems in psychiatry patients at tertiary care teaching hospital. Int J Pharma Sci Res. 2018;9(2):819-823.

4 Rawal KB, Chand S, Luhar MB, et al. A comparative study on relative safety and efficacy of chlorpromazine and risperidone. Int J Res Pharm Sci. 2020;11:1539-1544, 02 .

5 Rachana J, Shastry CS, Mateti UV, Sharma R, Nandakumar UP, Chand S. Incidence and associated factors of adverse drug reactions in the general medicine department of a tertiary care teaching hospital. International journal of pharmaceutical research. 2019;11(3):177-184.

6 Sah SK, Subramanian R, Ramesh M, Chand S. Impact of pharmacist care in the management of autoimmune disorders: a systematic review of randomized control trials and non-randomized studies. Res Soc Adm Pharm. 2020. https://doi.org/ 10.1016/j.sapharm.2020.12.005.

7 Voora L, Sah SK, Bhandari R, et al. Doctor of pharmacy: boon for healthcare system. Drug Invent Today. 2020;14(1):153-158.

8 Garin N, Sole N, Lucas B, et al. Drug related problems in clinical practice: a crosssectional study on their prevalence, risk factors and associated pharmaceutical interventions. Sci Rep. 2021;11:883. https://doi.org/10.1038/s41598-020-80560-2.

9 Mukherjee S, Sen S, Tripathi S, Chatterjee S, Era N, Ghosal M. Adverse drug reaction monitoring of antidepressants in the psychiatry outpatient department at a tertiary 
care teaching hospital in India: a cross-sectional observational study. Eur J Psychol Stud. 2015;2(1):14.

10 Grover S, Avasthi A, Sinha V, Lakdawala B, Bathla M, etal Sethi S. Indian Psychiatric Society multicentric study: prescription patterns of psychotropics in India. Indian $J$ Psychiatr. 2014;56(3):253.

11 Newman L, Harris V, Evans LJ, Beck A. Factors associated with length of stay in psychiatric inpatient services in london. Psychiatr Q. 2018;89:33-43.

12 Zolezzi M, AbdulrhimS, Isleem N, Zahrah F, Eltorki Y. Medical comorbidities in patients with serious mental illness: a retrospective study of mental health patients attending an outpatient clinic in Qatar. Neuropsychiatric Dis Treat. 2017;13: 2411-2418.

13 Singh P, Madiwalayya S, Bheemsain V. Clinical pharmacist assessment in monitoring and resolving the adverse drug reaction in bipolar disorder patients: a prospective, observational study at tertiary care teaching hospital. Int J Pharma Sci Res. 2019;12 (1):56.
14 Khoda DA, Ganachari MS, Wadhwa T, Walli S, Parihar B, Aggarwal A. Clinical Pharmacist driven impact towards intensive monitoring and reporting of Adverse Drug Effects in Psychiatric patients. J Pharmacovigilance. 2014;2(3):1-6.

15 Mateti UV, Lalwani T, Nagappa AN, Bhandary PV, Verupaksha D, Balkrishnan R. Assessment of drug related problems in depressive patients. PerspectClin Res. 2015;6 (1):58-61.

16 Sridhar S, Al-Thamer S, Jabbar R. Monitoring of adverse drug reactions in psychiatry outpatient department of a Secondary Care Hospital of Ras Al Khaimah, UAE. J Basic Clin Pharm. 2016;7(3):80.

17 AlRuthia Y, Alkofide H, Alosaimi F, Sales I, Alnasser A, etal Aldahash A. Drug-drug interactions and pharmacists' interventions among psychiatric patients in outpatient clinics of a teaching hospital in Saudi Arabia. SPJ. 2019;27(6):798-802.

18 Joseph JG, Prabhu S, Chand S, Roy DA, Nandakumar UP, Joel JJ. Assessment of metabolic risk factors in patients undergoing antipsychotic drug therapy: a Pharmacist-led study. Le Pharmacien Hospitalier et Clinicien. 2021. https://doi.org/ 10.1016/j.phclin.2021.03.005. 